\title{
Corn stalk-derived activated carbon with a stacking sheet-like structure as sulfur cathode supporter for lithium/sulfur batteries
}

\author{
Guanghui Yuan ${ }^{1}$ - Fuxing Yin ${ }^{2,3}$ - Yan Zhao ${ }^{2,3}$ - Zhumabay Bakenov ${ }^{4}$. \\ Gongkai Wang $^{2,3}$ • Yongguang Zhang ${ }^{2,3}$
}

Received: 8 April 2015 /Revised: 13 July 2015 / Accepted: 10 August 2015 / Published online: 2 September 2015

(C) Springer-Verlag Berlin Heidelberg 2015

\begin{abstract}
A novel stacking sheet-like carbon (SSC) has been synthesized by carbonizing the corn stalks and composited with sulfur to prepare a cathode for lithium/sulfur batteries. Scanning electronic microscopy observations showed the formation of irregularly interlaced nanosheet-like structure consisting SSC with uniform sulfur coating on its surface. The SSC nanoflakes in the composite act as nanocurrent collectors, favoring the charge carrier ion transport and electrolyte diffusion. The interlaced SSC nanoflakes irregularly stack together and form a three-dimensional network, which is beneficial for both trapping soluble polysulfide intermediates and rendering the electrical conductivity of the composite electrode. A lithium cell employing this sulfur/stacking sheetlike carbon (S/SSC) composite cathode delivered an initial discharge capacity of $965 \mathrm{mAh} \mathrm{g}^{-1}$ at $0.2 \mathrm{C}$ and retained a capacity of $743 \mathrm{mAh} \mathrm{g}^{-1}$ over 100 charge-discharge cycles. Even at $3.2 \mathrm{C}$ rate, the lithium cell with the S/SSC composite cathode demonstrated an excellent rate capability, delivering a highly reversible discharge capacity of $418 \mathrm{mAh} \mathrm{g}^{-1}$.
\end{abstract}

Keywords Corn stalk $\cdot$ Sulfur cathode $\cdot$ Sulfur/stacking sheet-like carbon composite $\cdot$ Lithium/sulfur battery

Yongguang Zhang

yongguangzhang@hebut.edu.cn

1 Department of Chemistry and Chemical Engineering, Ankang University, Shaanxi Ankang 725000, China

2 Research Institute for Energy Equipment Materials, Hebei University of Technology, Tianjin 300130, China

3 Tianjin Key Laboratory of Laminating Fabrication and Interface Control Technology for Advanced Materials, Hebei University of Technology, Tianjin 300130, China

4 Institute of Batteries LLC, Nazarbayev University Research and Innovation System, 53, Kabanbay Batyr Avenue, Astana 010000, Kazakhstan

\section{Introduction}

Rechargeable lithium-ion batteries, based on $\mathrm{Li}^{+}$intercalation electrodes, have become the dominant power source for various portable applications [1, 2]. However, the current cathode materials used in lithium-ion batteries, such as those based on transition metal oxides and phosphates, have an inherent theoretical capacity limit of $300 \mathrm{mAh} \mathrm{g}^{-1}$ and a maximum practically usable capacity of only $210 \mathrm{mAh} \mathrm{g}^{-1}$ reported, which cannot fully satisfy the application requirements for electric vehicles and large-scale energy storage, such as wind or solar energy storage [3-5]. The lithium/sulfur $(\mathrm{Li} / \mathrm{S})$ battery can offer a strikingly high theoretical specific capacity of approximately $1672 \mathrm{mAh} \mathrm{g}^{-1}$ and a theoretical specific energy of $2600 \mathrm{Wh} \mathrm{kg}^{-1}$, which is five times higher than that of $\mathrm{LiCoO}_{2}$ /graphite system [6]. Furthermore, sulfur is ecofriendly and abundantly available, which reduces the projected cost of Li/S batteries. Accordingly, the Li/S battery is considered as one of the judicious selections with respect to the advanced power supply in the near future. However, practical application of $\mathrm{S}$ as a cathode-active material in Li/S batteries has been plagued with its low electrical conductivity and high solubility of polysulfides in the electrolyte solutions [7]. To overcome these problems, one of the most promising methods is to fabricate sulfur/carbon composites. This is mainly because different kinds of carbonaceous supporters can act as a conductive network to facilitate electron migration and as a reservoir to adsorb the polysulfides formed upon a $\mathrm{Li} /$ $\mathrm{S}$ battery operation [8].

Many efforts have been dedicated to impregnating sulfur into various carbon matrixes. For example, mesoporous carbon $[9,10]$, microporous carbon [11], carbon fiber [12], carbon nanotubes [13-15], and graphene [16, 17] have been applied to improve the electrochemical properties of the S cathode. Although the S/carbon composites show good electrochemical performance, most of the preparation techniques of sulfur/carbon composites have disadvantages of prolonged 
and complicated processing and side products, which trade off the cost efficiency of the final product [18]. In contrast, biomass-derived carbon materials are abundant in raw sources and cheap; they are easily scalable in synthesis route [19]. Therefore, aiming to further ameliorate the expenses problem of the final product while maintaining the superior conductivity of the electrode materials, it is an intriguing inspiration to create sulfur/biomass-derived carbon composites. Corn is one of the most common crops in the earth, especially in China. The corn stalk is a good precursor to prepare a value-added carbonaceous material, possessing a negative value associated with their disposal. Corn stalks have been used to fabricate conventional activated carbons in the previous work [20]. However, to the best of our knowledge, there is currently no discussion and consideration of corn stalk-prepared carbon serving as a carbon supporter for sulfur composite cathode in $\mathrm{Li} / \mathrm{S}$ batteries.

Herein, we first report on a novel stacking sheet-like carbon (SSC) synthesized via carbonizing the corn stalks. Active sulfur is loaded to SSC via a simple impregnation and heat treatment to design a sulfur/stacking sheet-like carbon (S/SSC) composite. The structural properties of this $\mathrm{S} / \mathrm{SSC}$ composite and its electrochemical performance as the cathode for $\mathrm{Li} / \mathrm{S}$ battery have been investigated. The resulting composite cathode demonstrates excellent electrochemical performance with good cyclability, rate capability, and high utilization of sulfur. The synergetic effects of stacking structure, thin sheets, and irregularly wrinkled surface of SSC on the electrochemical performance of the S/SSC cathode are investigated in detail.

\section{Experimental}

\section{Material preparation}

The corn (Zea mays) stalks used in the experiments were collected from Wuli Town, a region of Ankang City in China. SSC was prepared by thermal carbonization of the corn stalks followed with activation by $\mathrm{KOH}$. Firstly, the collected corn stalks were extensively washed with deionized (DI) water, cut into small pieces, and dried at $120{ }^{\circ} \mathrm{C}$ in a vacuum oven for $24 \mathrm{~h}$. Then, typically a 10 -g sample of corn stalk precursor was heated in a tubular furnace at $300{ }^{\circ} \mathrm{C}$ for $5 \mathrm{~h}$ (heating rate $\left.5{ }^{\circ} \mathrm{C} \mathrm{min}{ }^{-1}\right)$ under Ar flow $(150 \mathrm{sccm})$ to proceed with the pyrolysis carbonization. Further, the obtained sample was carefully immersed and kept overnight in $8 \mathrm{~mol} \mathrm{dm}^{-1} \mathrm{KOH}$ solution and then separated by centrifugation and dried. The role of $\mathrm{KOH}$ solution was to dissolve the by-product tar and to form pore structures during the following activation stage. Further, the powder was transferred into a tubular furnace and heated in Ar with a rate of $5^{\circ} \mathrm{C} \min ^{-1}$ to $550{ }^{\circ} \mathrm{C}$ and kept at this temperature for $4 \mathrm{~h}$ to obtain the black SSC product. Finally, the black SSC was ground and washed by $2 \mathrm{~mol} \mathrm{dm}^{-1}$ $\mathrm{HCl}$ and DI water until the washing solution $\mathrm{pH}$ reached 7.0, and dried in vacuum at $150{ }^{\circ} \mathrm{C}$ overnight.

The S/SSC composite was prepared by simple impregnation of sulfur into SSC and followed by heat treatment. The procedure is schematically illustrated in Fig. 1. Firstly, S was dissolved in carbon disulfide $\left(\mathrm{CS}_{2}\right)$ to form a $50 \% \mathrm{~S} / \mathrm{CS}_{2}$ solution. Then, the $\mathrm{S} / \mathrm{CS}_{2}$ solution was dropped on the $\mathrm{SSC}$, rapidly adsorbed by the $\mathrm{SSC}$. After evaporation of $\mathrm{CS}_{2}$, the sulfur adsorption process was repeated several times to achieve a desired weight loading of sulfur. In order to deposit S homogeneously, the obtained black powder was transferred into a Teflon autoclave, filled with $\mathrm{N}_{2}$, sealed and maintained at $155^{\circ} \mathrm{C}$ for $10 \mathrm{~h}$, and then naturally cooled down to ambient temperature. Finally, the resulting sample was dried at $60^{\circ} \mathrm{C}$ in a vacuum oven for $24 \mathrm{~h}$ to obtain the S/SSC composite.

\section{Material characterization}

Powder X-ray diffraction (XRD) patterns of samples were obtained using a Bruker D8 Advance X-ray powder diffractometer using $\mathrm{Cu} \mathrm{K} \alpha$ radiation $(\lambda=0.15418 \mathrm{~nm})$ at a scanning rate of $0.02^{\circ} \mathrm{s}^{-1}$ in the $2 \theta$ range from $10^{\circ}$ to $70^{\circ}$. The BrunauerEmmett-Teller (BET) surface area and the Barret-JoynerHalenda $(\mathrm{BJH})$ pore size distribution of the samples were measured at $77 \mathrm{~K}$ (BET, ASAP 2020; Micromeritics).

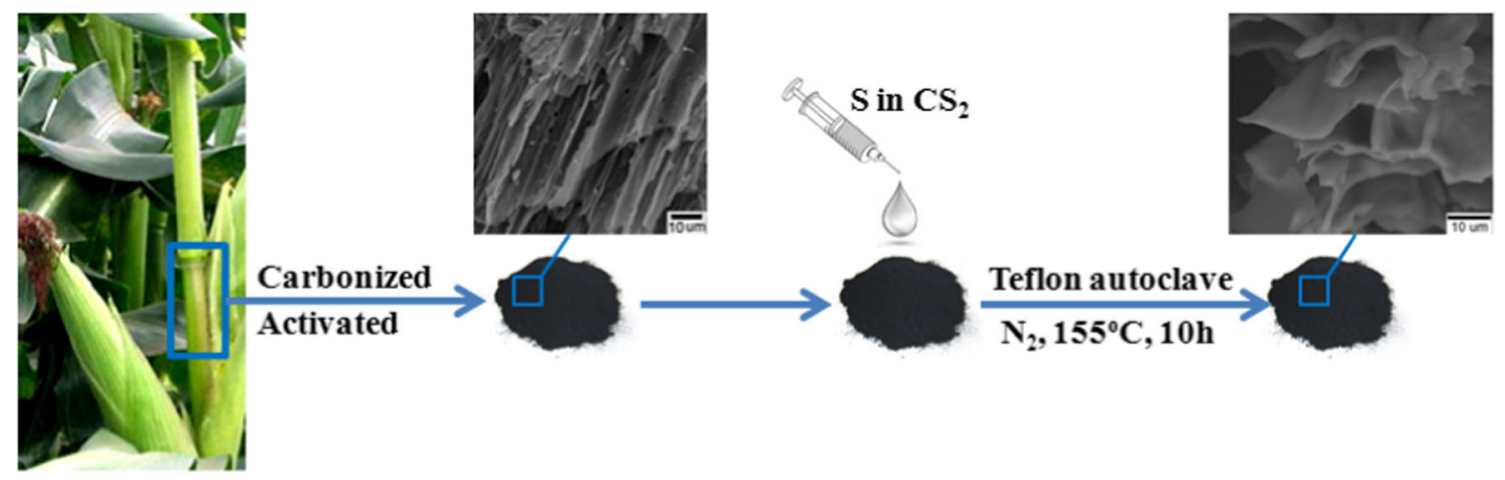

Fig. 1 Schematics of the S/SSC composite synthesis process 
Scanning electron microscopy (SEM) images were obtained using a FEI Quanta 400 ESEM-FEG (environmental scanning electron microscope-field emission gun) equipped with an Xray energy-dispersive spectrometer (EDS). Thermogravimetric analysis (TGA) was performed on a thermoanalyzer (DSCTGA; SDT Q600; American TA Company) in the temperature range of $20-500{ }^{\circ} \mathrm{C}\left(10^{\circ} \mathrm{C} \mathrm{min}^{-1}\right)$ under $\mathrm{N}_{2}$ atmosphere, with a flow rate of $50 \mathrm{~mL} \mathrm{~min}$. The interior structure of sample was observed by transmission electron microscopy (TEM, JEM-2100F, JEOL) at $120 \mathrm{kV}$.

\section{Electrochemical measurement}

The S/SSC electrodes were prepared by mixing $75 \mathrm{wt} \%$ asprepared composite, $15 \mathrm{wt} \%$ acetylene black, and $10 \mathrm{wt} \%$ polyvinylidene fluoride in 1-methyl-2-pyrrolidinone. The sulfur loading in each electrode was about $1 \mathrm{mg} \mathrm{cm}^{-2}$. Lithium foil was used as a counter electrode; $1 \mathrm{~mol} \mathrm{dm}^{-1} \mathrm{LiCF}_{3} \mathrm{SO}_{3}$ solution was prepared in a mixture of 1,2-dimethoxyethane (DME) and 1,3-dioxolane (DOL) $(1: 1, v / v)$ and used as an electrolyte. $\mathrm{A} \mathrm{LiNO}_{3}$ salt $(1 \mathrm{wt} \%)$ was added into the electrolyte. The separator was microporous polypropylene film. Coin-type (CR2025) cells were assembled in a glove box filled with Ar. The charge-discharge tests were carried out on a LAND battery program-control test system in a cutoff
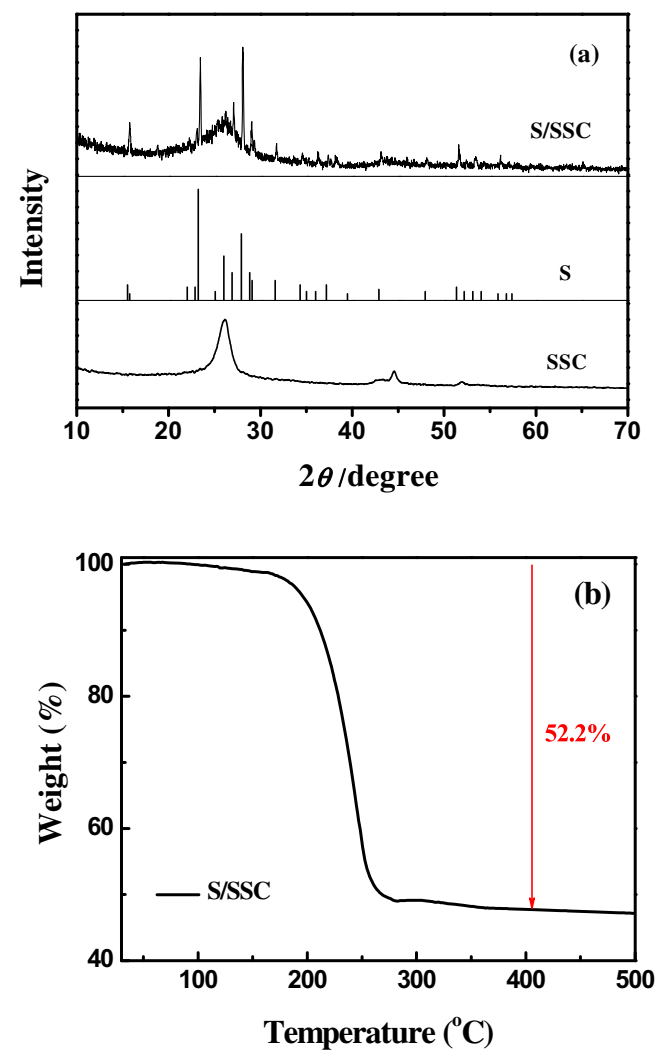

Fig. 2 a XRD patterns of sulfur, SSC, and S/SSC composite. b TGA curve of the S/SSC composite potential window of 1.0-3.0 V vs. $\mathrm{Li}^{+} / \mathrm{Li}$. Cyclic voltammetry (CV) was carried out on a $\mathrm{CHI} 660 \mathrm{D}$ electrochemical workstation at a scan rate of $0.1 \mathrm{mV} \mathrm{s}^{-1}$ in the potential range of $1.0-3.0 \mathrm{~V}$ vs. $\mathrm{Li} / \mathrm{Li}^{+}$. Electrochemical impedance spectroscopy (EIS) was measured using the same electrochemical work station within a frequency range from 0.01 to $100 \mathrm{kHz}$. The no-additive sulfur electrodes were also prepared for comparison using the same technology.

\section{Results and discussion}

The crystal structures of the obtained materials were firstly investigated by XRD. Figure 2a shows the XRD patterns of SSC, S, and S/SSC composite. The synthesized SSC displays a strong diffraction peak at around $26^{\circ}$, which can be ascribed to the (002) reflection of carbon [21]. The S/SSC composite gives obvious peaks at $23.1^{\circ}, 25.9^{\circ}, 27.8^{\circ}, 28.7^{\circ}, 31.5^{\circ}, 37.1^{\circ}$, $42.8^{\circ}, 47.8^{\circ}$, and $51.3^{\circ}$, which are typical signals from orthorhombic sulfur (JCPDS \#08-0247) [22]. In addition, the $\mathrm{S} / \mathrm{SSC}$ composite displays a broad diffraction peak at around $26^{\circ}$, belonging to the (002) reflection of carbon. All the XRD patterns indicate that the S/SSC composite was successfully synthesized using the current synthesis method. Furthermore, no peak shift could be observed, which could be an indication of absence of phase transformations during sulfur
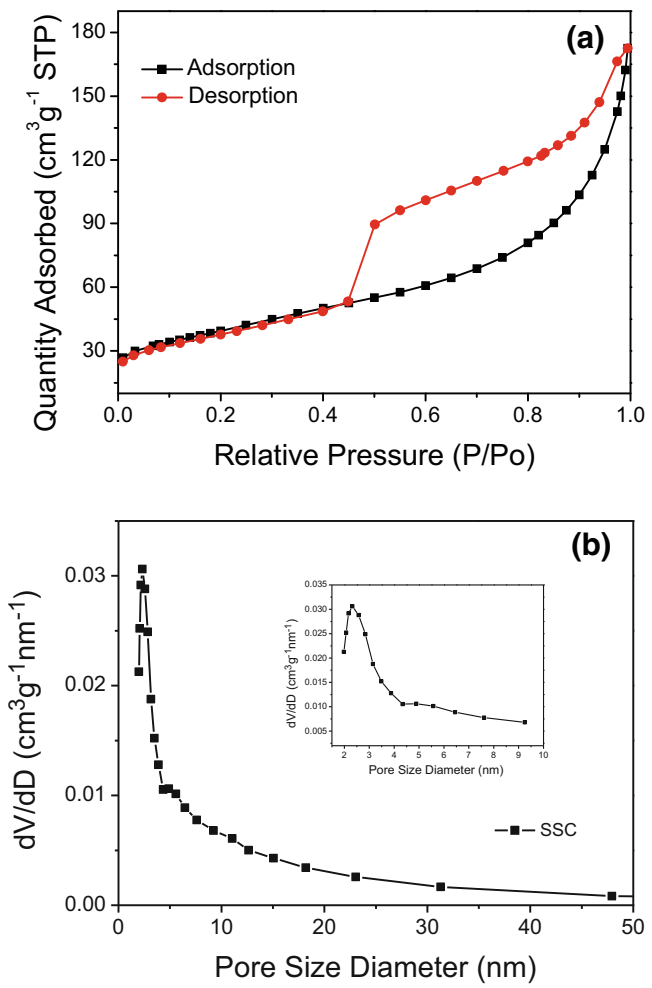

Fig. 3 a $\mathrm{N}_{2}$ adsorption-desorption isotherm of SSC. b Pore size distribution of the SSC 
impregnation and heat treatment, and the sulfur crystal structure remained in the $\mathrm{S} / \mathrm{SSC}$ composite. The sulfur content in the S/SSC composite was estimated by TGA. As shown in Fig. 2b, the TGA curve exhibits an obvious one-step weight loss from around 160 to $320{ }^{\circ} \mathrm{C}$, which is assigned to the evaporation of sulfur [23]. Subsequently, the carbon material remains almost unchanged up to $500{ }^{\circ} \mathrm{C}$. The TGA data show that the final sulfur content of approximately $52.2 \mathrm{wt} \%$ in the S/SSC composite was achieved.

The results of the surface area and pore size distribution studies of the as-prepared SSC are shown in Fig. 3. Figure 3a is the $\mathrm{N}_{2}$ adsorption-desorption isotherm of SSC. The isotherm profile can be indexed as type IV with an obvious revulsion at a low relative pressure of 0.44 , suggesting that SSC has mesoporous structure. According to the low critical relative pressure of SSC, we can conclude that the mesoporous size of SSC is small. The enclosed hysteresis loop of the adsorption-desorption isotherm can be categorized as type $\mathrm{H}_{3}$, indicating the channels and inhomogeneous pores existing in the SSC structure. The pore size distribution of SSC, as shown in Fig. 3b, and the pore size distribution curve indicate that the main small pore size lies in the 2-10 nm range, which conform with the $\mathrm{N}_{2}$ adsorption-desorption isotherm. The BET-specific surface area is measured to be $139.8 \mathrm{~m}^{2} \mathrm{~g}^{-1}$, and the pore volume and average pore size of SSC, calculated using the Barrett-Joyner-Halenda method, are $0.263 \mathrm{~cm}^{3} \mathrm{~g}^{-1}$ and $6.317 \mathrm{~nm}$, respectively. This highly mesoporous structure could be very beneficial for assuming optimized morphology and fast kinetics for sulfur cathode, confirming the following electrochemical studies results.

The morphology of the synthesized SSC and the S/SSC composite was investigated by SEM. Figure $4 \mathrm{a}, \mathrm{b}$ shows a typical SEM image of the SSC, from which one can see that the obtained SSC is composed and assembled by the
Fig. 4 SEM images of SSC $(\mathbf{a}, \mathbf{b})$ and $\mathrm{S} / \mathrm{SSC}$ composite (c) samples, carbon, and sulfur mapping of the S/SSC composite (d, e). TEM images of SSC (f) and $\mathrm{S} / \mathrm{SSC}$ composite (g)
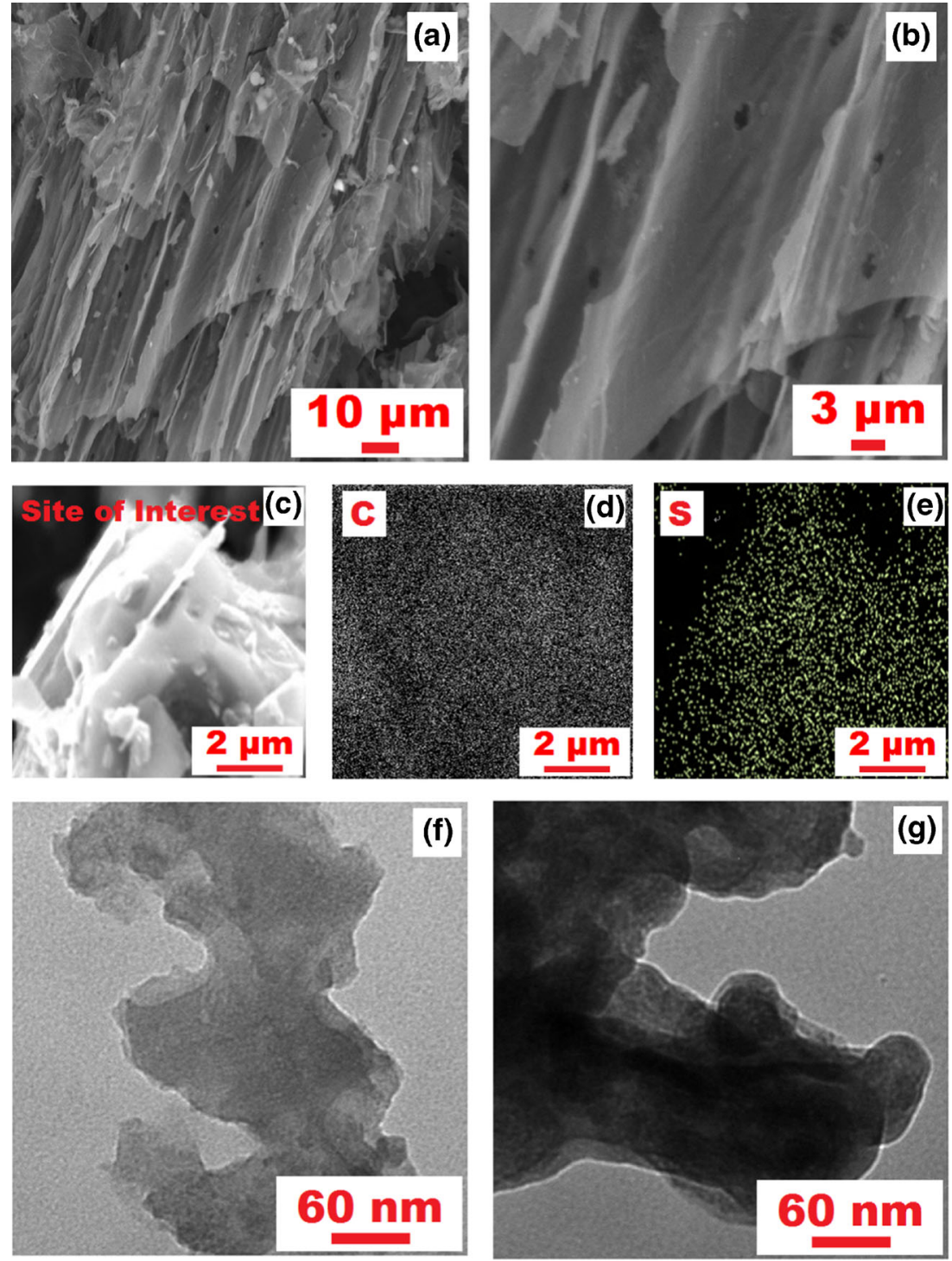
interlaced nanoflakes with irregularly wrinkled surface with porous structure. The SEM image of the S/SSC composite in Fig. $4 \mathrm{c}$ indicates that it forms irregular stacks of interlaced nanosheet-like structure, leading to a smooth surface, densely covered with sulfur. This is probably due to the high absorption ability of SSC towards sulfur [24]. It could be suggested that SSC nanosheets may act as nanocurrent collectors for the sulfur particles and enhance the conductivity of the composite [25]. On the other hand, hollow structure of the composite agglomerates creates the pathways for the electrolyte and Li-ion transport providing enhanced activity of the composite [26]. In order to investigate the distribution of sulfur in the S/SSC composite, the EDS mapping was obtained as presented in Fig. 4d, e. One can see that sulfur is homogeneously distributed in the S/SSC composite. This well-developed stacking sheet-like structure with homogeneous sulfur distribution enhances the contact of sulfur with the conductive SSC, positively affecting the overall electrochemical performance of the composite cathode material. The TEM results (Fig. 4f, g) confirm the formation of the flake-like structured SSC, and it can be clearly seen from the TEM images that SSC flakes are covered with sulfur, and irregular stacks of interlaced nanosheet-like structure were formed. It could be suggested the SSC acts as nanocurrent collectors of the S/SSC composite, enhancing the conductivity of the composite material.

Three initial CV curves of the S/SSC composite electrode were measured in the potential range of $1.0-3.0 \mathrm{~V} \mathrm{vs.} \mathrm{Li}^{+} / \mathrm{Li}$ at a scan rate of $0.1 \mathrm{mV} \mathrm{s}^{-1}$, as shown in Fig. 5a. The first CV curve shows typical characteristics of two major cathodic peaks of a Li/S system at about 2.37 and $2.05 \mathrm{~V}$. The cathodic peak at $2.37 \mathrm{~V}$ can be assigned to the reduction of sulfur $\left(\mathrm{S}_{8}\right)$ to polysulfides $\left(\mathrm{Li}_{2} \mathrm{~S}_{n}, n \geq 4\right)$, while the strong cathodic peak around $2.0 \mathrm{~V}$ is associated with the reduction of soluble polysulfides into $\mathrm{Li}_{2} \mathrm{~S}_{2} / \mathrm{Li}_{2} \mathrm{~S}[22,27]$. In the anodic scan, only one sharp anodic peak is observed around $2.5 \mathrm{~V}$, associated with the reoxidation of the discharge products $\left(\mathrm{Li}_{2} \mathrm{~S}\right.$ and $\mathrm{Li}_{2} \mathrm{~S}_{2}$ ) to $\mathrm{Li}_{2} \mathrm{~S}_{8}[28,29]$. In the following CV scans, the redox peak currents and potentials show no obvious change, indicating good reactive reversibility and cycling stability of the $\mathrm{S} / \mathrm{SSC}$ composite electrode. The galvanostatic chargedischarge curve of the S/SSC composite at the initial cycle at a current density of $0.1 \mathrm{C}\left(1 \mathrm{C}=1670 \mathrm{mAh} \mathrm{g}^{-1}\right)$ is shown in Fig. 5b. The S/SSC composite electrode shows two apparent plateaus in the discharge curve and one plateau in the charge curve, which are in good agreement with the $\mathrm{CV}$ data. Considering the capacity per $\mathrm{S}$ gram (similarly hereinafter), the S/SSC composite cell shows a high initial discharge capacity of $1337 \mathrm{mAh} \mathrm{g}^{-1}$ at the cycling rate of $0.1 \mathrm{C}$.

The cycle and rate performance are important challenging and key aspects for Li/S battery applications. The enhanced soluble product trapping capacity of the S/SSC composite with porous and loose architecture with uniform sulfur coating is reflected in the cycle performance enhancement. As shown in Fig. 6a, the S/SSC composite and sulfur electrodes deliver initial capacities of 965 and $735 \mathrm{mAh} \mathrm{g}^{-1}$ at $0.2 \mathrm{C}$, respectively. The discharge capacity of the sulfur cathode drastically decreases and maintains only $363 \mathrm{mAh} \mathrm{g}^{-1}$ after 100 cycles. In comparison with the sulfur cathode, the $\mathrm{S} / \mathrm{SSC}$ composite cathode exhibits a remarkably enhanced performance, delivering a high specific capacity of $743 \mathrm{mAh} \mathrm{g}^{-1}$. Furthermore, one may note from Fig. $6 \mathrm{a}$ that the coulombic efficiencies of both S/SSC composite and S electrodes are relatively low in the initial several cycles. This may be due to the fact that at these initial cycles, the untrapped polysulfides dissolve into the electrolyte and, thus, the occurred shuttle mechanism results in the faster capacity attenuation and lower coulombic efficiency upon initial cycling. After the initial activation, both S/SSC composite and sulfur cathodes maintain a high coulombic efficiency more than $95 \%$. Furthermore, the coulombic efficiency of S/SSC composite cathode is more reposeful than that of bare sulfur counterpart. This could be attributed to the porous hierarchical architectures assembled by the interlaced nanoflakes of S/SSC composite, suppressing the shuttle effect.

Simultaneously, the rate performance of the S/SSC composite cathode has also been improved comparing to $\mathrm{S}$ cathode, as it is demonstrated in Fig. 6b. The reversible capacities of $1393,973,741,618,511$, and $418 \mathrm{mAh} \mathrm{g}^{-1}$ of the S/SSC composite cathodes are achieved at the initial cycles at the current densities of $0.1,0.2,0.4,0.8,1.6$, and $3.2 \mathrm{C}$,
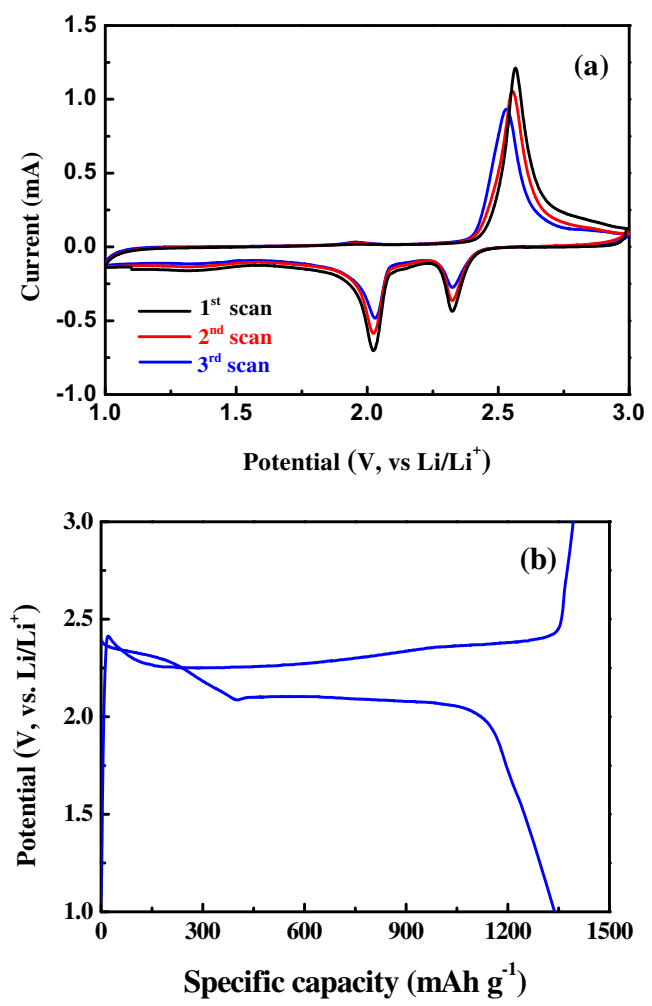

Fig. 5 a CV curves of the S/SSC electrode at $0.1 \mathrm{mV} \mathrm{s}^{-1}$. b Chargedischarge profiles of the $\mathrm{S} / \mathrm{SSC}$ electrode at $0.1 \mathrm{C}$; both are within 1.0 $3.0 \mathrm{~V}$ vs. $\mathrm{Li}^{+} / \mathrm{Li}$ 

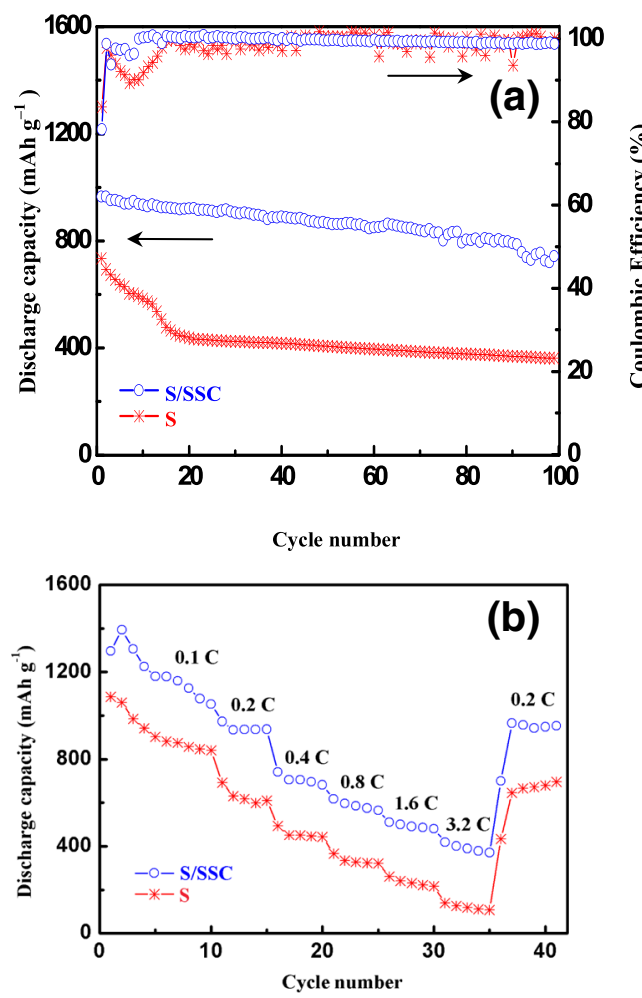

Fig. 6 Cycle performance of the S and S/SSC electrodes in a lithium cell at $0.2 \mathrm{C}$ rate (a) and the cell rate performance (b)

respectively. Although the capacity decreases gradually with the current density, when the discharge rate was reduced back to $0.2 \mathrm{C}$, the cell fully recovers its reversible capacity of $966 \mathrm{mAh} \mathrm{g}^{-1}$. In contrast, at the current rates of $0.1,0.2,0.4$, $0.8,1.6$, and $3.2 \mathrm{C}$, the $\mathrm{S}$ cathode achieves the initial discharge capacities of only 1086, 692, 493, 367, 261, and $139 \mathrm{mAh} \mathrm{g}^{-1}$, respectively. At each current rate, the S/SSC cathode reversible capacity is higher for $200-300 \mathrm{mAh} \mathrm{g}^{-1}$ compared with the $\mathrm{S}$ cathode. The rate performance improvement could be attributed to the combinative multiple effects of the SSC as conductor, sulfur distributor, and an active absorber for the electrochemical reaction products. The SSC nanoflakes in the composite could serve as nanocurrent collectors, favoring fast ion transport and electrolyte diffusion.

EIS is a powerful tool to study the effect of various additives on the conductivity and charge transfer behavior in composite cathode materials. EIS measurements for both the $\mathrm{S} / \mathrm{SSC}$ and S cathodes after the first charge and discharge are carried out, as shown in Fig. 7. For both cathodes, the Nyquist plots are represented by a semicircle in the high-tomedium-frequency region relating to the charge transfer resistance of the cathodes, followed by a declined straight line of the Warburg impedance in low-frequency part attributed to the $\mathrm{Li}^{+}$diffusion resistance of the cathodes [30]. In general, the smaller the diameter of a semicircle is, the lower the charge transfer resistance of an electrode. The bigger the slope of a line is, the lower the $\mathrm{Li}^{+}$diffusion resistance of an electrode.

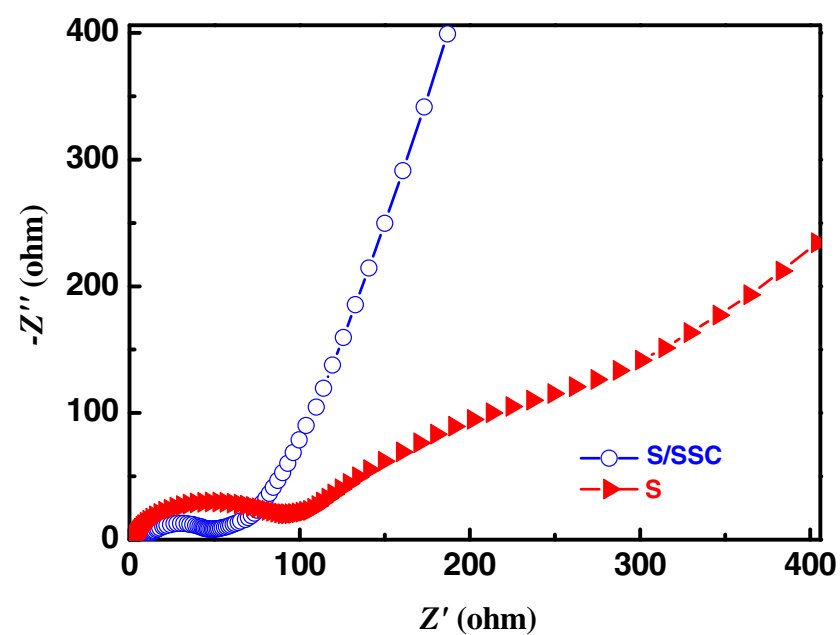

Fig. 7 Nyquist plots of the S and S/SSC cathodes after the first charge and discharge cycle

From Fig. 7, it can be easily observed that both the charge transfer resistance and the $\mathrm{Li}^{+}$diffusion resistance of the S/SSC composite cathode are obviously lower than that of the $\mathrm{S}$ cathode. The results support our above suggestion on the conducting property enhancement of the S/SSC composite cathode using a new SSC carbon supporter.

\section{Conclusions}

A novel stacking sheet-like carbon (SSC) has been synthesized by carbonizing the corn stalks followed by activation by KOH. This is a cost-effective, simple, and easy-to-scaleup technique for the material production. Based on the SSC material, a sulfur/stacking sheet-like carbon (S/SSC) composite has been successfully prepared via simple impregnation and heat treatment. When served as a cathode for lithium/ sulfur $(\mathrm{Li} / \mathrm{S})$ battery, the $\mathrm{S} / \mathrm{SSC}$ composite exhibited a high initial discharge capacity of $1337 \mathrm{mAh} \mathrm{g}^{-1}$ at $0.1 \mathrm{C}$. At the cycling rates of $0.2,0.4,0.8,1.6$, and $3.2 \mathrm{C}$, the $\mathrm{S} / \mathrm{SSC}$ cathode shows a high discharge capacity of $973,741,618,511$, and $418 \mathrm{mAh} \mathrm{g}^{-1}$, respectively. After a 100 cycle stability test, the specific capacity of S/SSC composite cathode delivers a discharge capacity up to $743 \mathrm{mAh} \mathrm{g}^{-1}$ at $0.2 \mathrm{C}$ with a high Coulombic efficiency of $98 \%$. The good electrochemical performance could be attributed to the porous hierarchical architectures assembled by the interlaced nanoflakes of S/SSC composite, which is providing high conductivity and short $\mathrm{Li}^{+}$diffusion distances as well as absorbing polysulfides to improve the cycle ability in $\mathrm{Li} / \mathrm{S}$ batteries.

Acknowledgments This work was supported by the Natural Science Foundation of Shaanxi Province (No. 2013JM2009). The authors YZ and YGZ are grateful to the financial support by the National Natural Science Foundation of China (Grant No. 21406052) and financial support by Program for the Outstanding Young Talents of Hebei Province (Grant 
No. BJ2014010). YGZ and ZB acknowledge the support from the subproject of the Technology Commercialization Project of the World Bank and the Government of Kazakhstan (Group 157).

\section{References}

1. Armand M, Tarascon JM (2008) Building better batteries. Nature 451:652-657

2. Zhao Y, Zhang Y, Gosselink D, Doan TNL, Sadhu M, Cheang HJ, Chen P (2012) Polymer electrolytes for lithium/sulfur batteries. Membranes 2:553-564

3. Zhang Y, Zhao Y, Sun KEK, Chen P (2011) Development in lithium/sulfur secondary batteries. Open Mater Sci J 5:215-221

4. Kim DK, Muralidharan P, Lee HW, Ruffo R, Yang Y, Chan CK, Peng H, Huggins RA, Cui Y (2008) Spinel $\mathrm{LiMn}_{2} \mathrm{O}_{4}$ nanorods as lithium ion battery cathodes. Nano Lett 8:3948-3952

5. Zhang Y, Bakenov Z, Zhao Y, Konarov A, Doan TNL, Sun KEK, Yermukhambetova A, Chen P (2013) Effect of nanosized $\mathrm{Mg}_{0.6} \mathrm{Ni}_{0.4} \mathrm{O}$ prepared by self-propagating high temperature synthesis on sulfur cathode performance in Li/S batteries. Powder Technol 235:248-255

6. Evers S, Nazar LF (2013) New approaches for high energy density lithium-sulfur battery cathodes. Acc Chem Res 46:1135-1143

7. Zhang Y, Zhao Y, Konarov A, Gosselink D, Soboleski HG, Chen P (2013) A novel sulfur/polypyrrole/multi-walled carbon nanotube nanocomposite cathode with core-shell tubular structure for lithium rechargeable batteries. Solid State Ionics 238:30-35

8. Zhang Y, Zhao Y, Konarov A, Gosselink D, Li Z, Chen P (2013) One pot approach to synthesize PPy@S core-shell nanocomposite cathode for Li/S batteries. J Nanoparticle Res 15:2007

9. Schuster J, He G, Mandlmeier B, Yim T, Lee KT, Bein T, Nazar LF (2012) Spherical ordered mesoporous carbon nanoparticles with high porosity for lithium-sulfur batteries. Angew Chem Int Ed 51: 3591-3595

10. Zhao Y, Zhang Y, Bakenov Z, Chen P (2013) Electrochemical performance of lithium gel polymer battery with nanostructured sulfur/ carbon composite cathode. Solid State Ionics 234:40-45

11. Zhang B, Qin X, Li GR, Gao XP (2010) Enhancement of long stability of sulfur cathode by encapsulating sulfur into micropores of carbon spheres. Energy Environ Sci 3:1531-1537

12. Zhang Y, Bakenov Z, Zhao Y, Konarov A, Wang Q, Chen P (2014) Three-dimensional carbon fiber as current collector for lithium/ sulfur batteries. Ionics 20:803-808

13. Yuan GH, Xiang JM (2013) Facile synthesis of a sulfur/multiwalled carbon nanotube nanocomposite cathode with core-shell structure for lithium rechargeable batteries. Ionics 19:1449-1453

14. Chen SQ, Huang XD, Liu H, Sun B, Yeoh WK, Li KF, Zhang JQ, Wang GX (2014) 3D hyperbranched hollow carbon nanorod architectures for high-performance lithium-sulfur batteries. Adv Energy Mater 4:1301761

15. Zhang Y, Zhao Y, Bakenov Z, Tuiyebayeva M, Konarov A, Chen P (2014) Synthesis of hierarchical porous sulfur/polypyrrole/ multiwalled carbon nanotube composite cathode for lithium batteries. Electrochim Acta 143:49-55

16. Li J, Li K, Li MQ, Gosselink D, Zhang Y, Chen P (2014) A sulfurpolyacrylonitrile/graphene composite cathode for lithium batteries with excellent cyclability. J Power Sources 252:107-112

17. Zhang Z, Zhao Y, Bakenov Z, Babaa MR, Konarov A, Ding C, Chen P (2013) Effect of graphene on sulfur/polyacrylonitrile nanocomposite cathode in high performance lithium/sulfur batteries. J Electrochem Soc 160:A1194-A1198

18. Zhang Y, Zhao Y, Konarov A, Li Z, Chen P (2015) Effect of mesoporous carbon microtube prepared by carbonizing the poplar catkin on sulfur cathode performance in $\mathrm{Li} / \mathrm{S}$ batteries. J Alloys Compd 619:298-302

19. Ma YW, Zhao J, Zhang LR, Zhao Y, Fan QL, Li XA, Hu Z, Huang W (2011) The production of carbon microtubes by the carbonization of catkins and their use in the oxygen reduction reaction. Carbon 49:5292-5297

20. Li Y, Xu L, Chen T, Liu X, Xu Z, Zhang H (2012) Carbon nanoparticles from corn stalk soot and its novel application as stationary phase of hydrophilic interaction chromatography and per aqueous liquid chromatography. Anal Chim Acta 726:102-108

21. Endo M, Takeuchi K, Hiroka T, Furuta T, Kasai T, Sun X, Kiang $\mathrm{CH}$, Dresselhaus MS (1997) Stacking nature of graphene layers in carbon nanotubes and nanofibres. J Phys Chem Solids 58:17071713

22. Zhang Y, Bakenov Z, Zhao Y, Konarov A, Doan TNL, Malik M, Paron T, Chen P (2012) One-step synthesis of branched sulfur/ polypyrrole nanocomposite cathode for lithium rechargeable batteries. J Power Sources 208:1-8

23. Guo JC, Xu YH, Wang CS (2011) Sulfur-impregnated disordered carbon nanotubes cathode for lithium-sulfur batteries. Nano Lett 11: 4288-4294

24. Zhang Y, Zhao Y, Konarov A, Gosselink D, Soboleski HG, Chen P (2013) A novel nano-sulfur/polypyrrole/graphene nanocomposite cathode with a dual-layered structure for lithium rechargeable batteries. J Power Sources 241:517-521

25. Zhang Y, Zhao Y, Bakenov Z (2014) A novel lithium/sulfur battery based on sulfur/graphene nanosheet composite cathode and gel polymer electrolyte. Nanoscale Res Lett 9:137

26. Zhang Y, Zhao Y, Bakenov Z (2014) A simple approach to synthesize nanosized sulfur/graphene oxide materials for highperformance lithium/sulfur batteries. Ionics 20:1047-1050

27. Li X, Lushington A, Liu J, Li R, Sun X (2014) Superior stable sulfur cathodes of Li-S batteries enabled by molecular layer deposition. Chem Commun 50:9757-9760

28. Ding B, Yuan C, Shen L, Xu G, Nie P, Zhang X (2013) Encapsulating sulfur into hierarchically ordered porous carbon as a high-performance cathode for lithium-sulfur batteries. Chem Eur J 19:1013-1019

29. Li G, Li G, Ye S, Gao X (2012) A polyaniline-coated sulfur/carbon composite with an enhanced high-rate capability as a cathode material for lithium/sulfur batteries. Adv Energy Mater 2:1238-1245

30. Kim J, Lee DJ, Jung HG, Sun YK, Hassoun J, Scrosati B (2013) An advanced lithium-sulfur battery. Adv Funct Mater 23:1076-1080 